\title{
Transformações no mundo do trabalho e estratégias de controle do capital sobre o trabalhador
}

\author{
Izamara Nunes Sousa ${ }^{1}$ \\ Cinara Barbosa Franco de Sá ${ }^{2}$
}

\section{Resumo}

O presente artigo tem como objetivo pontuar algumas transformações no mundo do trabalho e suas implicações para a classe trabalhadora. Ressalta algumas das principais formas de "gestão" do trabalhador utilizadas atualmente que na verdade representam mecanismos estratégicos de controle sobre o trabalho e extração da mais-valia.

Palavras-chave: Mundo do Trabalho; Classe Trabalhadora; Controle sobre o trabalhador.

\begin{abstract}
The present article aims to highlight some transformations in the world of work and its implications for the working class. It highlights some of the main forms of "management" of the worker currently used that actually represent strategic mechanisms of control over labor and extraction of surplus value.

Key-words: World of Work; Working class; Control over the worker.
\end{abstract}

\section{Introdução}

Das "palestras" e "cursos" feitos dentro dos locais de trabalho a exemplo do coaching, até os livros de "autoajuda" que falam sobre a falácia da "empregabilidade como ter trabalho e remuneração sempre" (Minarelli, 1995); "saber desenvolver a criatividade na vida e no trabalho" (Bouillerce, 2004) até aqueles que falam sobre "como

\footnotetext{
${ }^{1}$ Estudante de Programa de Mestrado em Desenvolvimento Sócioespacial e Regional da Universidade Estadual do Maranhão (UEMA). Email: izasousakids985@gmail.com.

${ }^{2}$ Estudante de Programa de Mestrado em Desenvolvimento Sócioespacial e Regional da Universidade Estadual do Maranhão (UEMA). Email: cinarafs2001@yahoo.com.br
} 
saber administrar o estresse na vida e no trabalho" (Cungi, 2004), estamos diante de uma sociedade que procura ao máximo extrair a mais-valia, criando e recriando formas de controle sobre o trabalhador (Marx, 1985).

Palavras como empregabilidade, autonomia, trabalho em equipe, motivação, rendimento e sucesso no trabalho, capacidade de autoliderança, desenvolvimento pessoal e empreendedorismo são termos que tem se tornado comum não apenas no cotidiano daqueles que ainda conseguem algum tipo de trabalho, mas também daqueles que fazem parte do exército sobrante. Exército este que chega a quase 13 milhões somente no Brasil!

Neste artigo, procuramos pontuar algumas maneiras que têm sido criadas e por vezes reatualizadas como mecanismos estratégicos de controle sobre o trabalho. Partimos assim da análise de alguns autores como Dal Rosso (2008), Antunes (2012), Marx (1985), Mészàros (2002), Gramsci (2002), Harvey (1982) e Dejours (2015), os quais abordam a temática a partir de várias perspectivas.

Abordamos também algumas questões referentes a dados extraídos de uma pesquisa, ainda em fase inicial, a respeito das principais formas de "gestão" exercidas sobre os trabalhadores em uma rede de supermercados em São Luís - MA.

\section{Formas de controle sobre o trabalhador no padrão Fordista/Taylorista ${ }^{3}$ e tendências atuais}

Sobre as formas de controle sobre o trabalhador no padrão fordista/taylorista, podemos inicialmente colocar que, se antes, na época do Fordismo, havia a figura clara do chefe, supervisor, ou seja, da pessoa que era responsável por olhar, supervisionar, vigiar os trabalhadores e suas atividades na fábrica, hoje, época de expansão do toyotismo, em um contexto de retrocesso de direitos fundamentais e de erosão das

\footnotetext{
${ }^{3}$ Segundo Antunes (2012, p.24), o Fordismo foi fundamentalmente a forma pela qual a indústria e o processo de trabalho consolidaram-se ao longo deste século, cujos elementos constitutivos básicos eram dados pela produção em massa, através da linha de montagem e de produtos mais homogêneos; através do controle dos tempos e movimentos, pelo cronômetro taylorista e da produção em série fordista; pela existência do trabalho parcelar e pela fragmentação das funções; pela separação entre elaboração e execução no processo de trabalho; pela existência de unidades fabris concentradas e verticalizadas e pela constituição/consolidação do operário-massa, do trabalhador coletivo fabril, entre outras dimensões.
} 
formas de suprimento das necessidades mais básicas do ser humano, o autocontrole tem se tornado uma ferramenta chave no processo de exploração do trabalhador ou da classe que vive do trabalho nos termos de Antunes (2012).

Por outro lado, podemos ainda inferir que esse processo de "autogestão" fortalecido ainda pelo enorme contingente de pessoas desempregadas acarreta um enfraquecimento da solidariedade intra-classe entre os trabalhadores, em que a relação de união e cooperação torna-se mais frágil. Se antes, na época do fordismo os trabalhadores estavam reunidos no chão da fábrica, organizando-se coletivamente em uma luta por direitos; hoje a própria reunião dos trabalhadores e consciência de pertencimento de classe torna-se um desafio.

A classe trabalhadora não é mais a mesma da época do fordismo. Ela metamorfoseou-se conforme aponta Antunes:

\footnotetext{
De um lado verificou-se uma desproletarização do trabalho industrial, fabril, nos países de capitalismo avançado, com maior ou menor repercussão em áreas industrializadas do terceiro mundo. Em outras palavras, houve uma diminuição da classe operária industrial tradicional. Mas, paralelamente, efetivou-se uma expressiva expansão do trabalho assalariado, a partir da enorme ampliação do assalariamento no setor de serviços (Antunes, 2012, p. 61)
}

Vivemos assim na época em que grande parte das funções estão relacionadas ao "setor de serviços", produzindo pincipalmente bens imateriais (Antunes, 2005). Além disso, as "novas" formas de exploração do trabalho a exemplo dos trabalhos temporários, sem contrato, sem vínculo empregatício, da remuneração por produção ou bem produzido são exemplos concretos de uma tendência em curso que afeta diretamente a classe que vive do trabalho.

Como resultado também da crise estrutural do capitalismo, as taxas de desemprego têm sido crescentes, um problema que conforme aponta Mészàros, "não mais se restringe à difícil situação dos trabalhadores não qualificados, mas atinge também um grande número de trabalhadores altamente qualificados" (Mészàros, 2002, p.1005) 
Para Dal Rosso (2008), vivenciamos também um processo de intensificação do trabalho. Fenômeno que iniciou por volta de 1980 e se estende até os dias de hoje, ressalta o autor.

E o que é intensificação ou intensidade do trabalho?

Dal Rosso responde:

A intensidade é, portanto, mais que esforço físico, pois envolve todas as capacidades do trabalhador, sejam as de seu corpo, a acuidade de sua mente, afetividade despendida ou os saberes adquiridos através do tempo ou transmitidos pelo processo de socialização (Dal Rosso, 2008, p. 21)

Estamos falando, portanto, de um processo de envolvimento do trabalhador que muitas das vezes não tem consciência dos mecanismos a ele impostos como estratégia para extrair não apenas as suas energias físicas, mas também mentais, intelectuais e subjetivas.

Partindo desta afirmação, precisamos esclarecer primeiramente que trabalho, conforme Marx é "condição natural da existência humana, uma condição do metabolismo entre homem e natureza independentemente de qualquer forma social" (Marx, 1982, p.37) e que o homem ao planejar em seu cérebro aquilo que irá produzir, "põe em movimento as forças naturais de seu corpo, braços e pernas, cabeça e mãos, a fim de apropriar-se dos recursos da natureza, imprimindo-lhe forma útil à vida humana" (Marx, 1985b, p.202). Portanto, trabalho é dispêndio de energia.

O argumento de Taylor na época do taylorismo era que toda essa energia do homem deveria ser canalizada para o trabalho e que, portanto, tudo aquilo que de alguma forma direcionasse esta energia que não fosse para a reprodução do trabalhador deveria ser abolida ou controlada por algum meio. Daí é que surgem diferentes modos de controle sobre o trabalhador na época que vão desde a utilização de um supervisor para controlar os ritmos de trabalho, até as estratégias de controle da vida fora do trabalho.

Seu objetivo último era assim a produtividade deste trabalhador. Este deveria produzir ao máximo as mercadorias em um menor tempo possível. Racionalização da produção; aumento da produtividade do trabalho; corte de "gastos desnecessários de energia" e de "comportamentos supérfluos" por parte do trabalhador eram as palavras de ordem do novo sistema que deveria acabar com qualquer "desperdício" de tempo. 
Como ressalta Gramsci, era necessário "um novo tipo humano, adequado ao novo tipo de trabalho e de processo produtivo". (Gramsci, 1934, p. 248)

No trabalho taylorizado, a divisão de tarefas é crucial. E muito embora eles convivam no mesmo ambiente de trabalho sob a disciplina da estrutura organizacional da fábrica, a individualidade do trabalhador é reforçada já que o novo método organizacional é executado de uma forma que os intervalos entre uma tarefa e outra sejam o mínimo possível e fazendo assim com que o contato, a comunicação de um trabalhador com outro fosse o mais possível de ser anulada.

Taylor, neste sentido, cria uma forma de vigiar este operário e assim de controlar cada gesto. É ai que entra a figura do supervisor:

Taylor imaginou então um meio de vigiar cada gesto, cada sequência, cada movimento na sua forma e no seu ritmo, dividindo o modo operatório complexo em gestos elementares mais fáceis de controlar por unidades, do que o processo no seu conjunto. Ele sistematizou este método e o instituiu em princípio: vários gestos não deviam mais ser executados por um só operário, sem que entre cada um deles se interpusesse uma intervenção de direção. Encontra lugar aqui o pessoal da vigilância. Fracionamento máximo e rigidez intangível da organização do trabalho aparecem, então, como as características fundamentais do novo sistema. (Dejours, 2015, p.48)

Além desse controle no local do trabalho, reforçado ainda pelos processos de treinamento e adestramento para conceber este novo operário- padrão, adequado ao novo modo de produção e organização do trabalho, era necessário um controle fora do local de trabalho; condição fundamental para a reprodução deste trabalhador e sua produtividade no local de trabalho.

É interessante apontar neste sentido que a necessidade de estabelecer práticas voltadas para inculcar nos trabalhadores um modo de vida nos locais fora do trabalho foi muito importante. O padrão de acumulação e superexploração que se estabelecia naquele momento, especialmente antes da primeira Guerra Mundial e imediatamente ao pós-guerra, trouxe a necessidade de se estabelecer mecanismos de consentimento da classe trabalhadora principalmente com o agravamento da questão social. Era, portanto, necessário um controle da grande massa de trabalhadores que agora também 
representavam uma ameaça, pois diante do profundo quadro de pauperização, estavam se organizando politicamente.

É neste momento que surgem algumas profissões como é o caso do Serviço Social, demandado à época como uma profissão que mediará a relação entre algumas necessidades da classe trabalhadora e o controle por parte do capital com o intuito de se obter o consentimento dos trabalhadores ao novo sistema de trabalho fordista/taylorista.

Sobre o assunto, David Harvey, ao analisar a necessidade de adequação dos trabalhadores ao novo padrão de produção nos países de capitalismo avançado ressalta que

\begin{abstract}
Essa necessidade de socializar a força de trabalho a um processo de trabalho, através de um controle exercido no local onde ela vive, é endêmica no capitalismo, mas é particularmente notável quando são introduzidos novos tipos de processo de trabalho. 0 dia de cinco dólares e oito horas na linha de montagem, introduzido por Henry Ford em 1914, foi acompanhado de muita retórica puritana e de um "filantrópico" sistema de controle que afetava praticamente todas as facetas da vida do trabalhador. Uma equipe de mais de trinta pesquisadores... visitava a casa dos trabalhadores, recolhendo informações e dando conselhos sobre detalhes íntimos do orçamento familiar, dieta, arranjos de vida, recreação, vida social e moral... o operário que se recusasse a aprender inglês, rejeitasse os conselhos do funcionário, jogasse ou bebesse em excesso, ou fosse considerado culpado de qualquer prática maliciosa, prejudicial á virilidade física ou caráter moral... estava desqualificado para o salário de cinco dólares. (Harvey, 1982, p. 22)
\end{abstract}

Portanto, na época do Fordismo/taylorismo as formas de controle tanto nos locais de trabalho como nos espaços de reprodução da vida eram vitais ao novo modo de organização do trabalho.

Nos dias atuais, essas inúmeras formas de controle do trabalhador continuam, não significando assim que o padrão fordista/taylorista tenha sido extinto. Ao contrário, novos elementos surgem com o toyotismo e ao mesmo tempo são reatualizados mecanismos anteriormente impostos.

Neste ínterim, David Harvey (2012) fala da acumulação flexível, mecanismo fundamental para exploração do trabalhador e acumulação capitalista tendo em vista as constantes crises do capital relacionadas à queda da taxa média de lucro. Destaca-se neste sentido, que a acumulação flexível, para além de buscar novos métodos organizacionais no processo produtivo, principalmente com a adoção das novas 
tecnologias, faz com que de fato o emprego seja cada vez mais flexível, isto é, que a quantidade de empregos estáveis sejam cada vez menor e a legislação social seja cada vez mais "aberta" para mudanças de exploração do trabalhador, conforme afirma Vasapollo:

Flexibilização pode ser entendida, por exemplo, como:

- Liberdade da empresa para despedir parte de seus empregados, sem penalidades, quando a produção e as vendas diminuem;

- Liberdade da empresa para reduzir ou aumentar o horário de trabalho, repetidamente e sem aviso prévio, quando a produção necessite;

- Faculdade da empresa de pagar salários reais mais baixos do que a paridade de trabalho, seja para solucionar negociações salariais, seja para poder participar de uma concorrência internacional;

- Possibilidade de a empresa subdividir a jornada de trabalho em dia e semana de sua conveniência, mudando os horários e as características (trabalho por turno, por escala, em tempo parcial, horário flexível, etc.) (Vasapollo, 2006, p.45)

O Estado neste sentido entra como uma espécie de "suporte" para que todos os processos de exploração do trabalhador pelo capital sejam considerados "legais". O Estado se coloca, assim como uma peça-chave para dar força e encaminhar os objetivos do empresariado. Ele cria as condições jurídicas para tal exploração. Como observa Gramsci, “através do 'direito', o Estado torna 'homogêneo' o grupo dominante e tende a criar um conformismo social que seja útil à linha de desenvolvimento do grupo dirigente" (Gramsci, 2000, p. 240).

Exemplo disto pode ser observado nas mudanças recentes nas Leis trabalhistas brasileiras que afetam consideravelmente a possibilidade de segurança em um emprego e, portanto, de reprodução da vida já que trabalho é fundamental para a manutenção e reprodução dos indivíduos.

Sob a retórica de "modernização" da CLT é que a dita "reforma" trabalhista ocorreu da mesma forma que as mudanças na organização do trabalho na época do fordismo/taylorismo e hoje no toyotismo. Tais "reformas" são colocadas assim com um tom messiânico de avanço e melhoria para todos.

Além disso, importa destacar que a referida reforma trouxe como uma das estratégias mais perversas para a classe trabalhadora e fundamental para o capitalismo 
a intimidação do trabalhador em relação à luta por seus direitos. Exemplo disto é a queda considerável do número de processos ajuizados em varas trabalhistas com as novas alterações na CLT. Mensalmente antes da reforma, as ações recebidas em primeira instância por tribunais trabalhistas eram cerca de 200 mil, caindo para 82,2 mil em dezembro de 2017. (Estadão, 2018)

Tal fator se deve, dentre outras coisas, às chamadas despesas de sucumbência, ou seja, o trabalhador que perde no julgamento uma ação trabalhista por ele demandada tem a obrigação de pagar honorários periciais e advogatícios da parte vencedora. Ora, tal mudança não é sem motivos: ela fragiliza o trabalhador que já vive em um contexto de insegurança e instabilidade e o inibe de lutar por seus direitos.

Em relação a estas reformas, Mandel ressalta que

O Estado procura constantemente transformar qualquer rebelião
em reformas que o sistema possa absorver, e procura solapar a
solidariedade na fábrica e na economia (por exemplo: pela
introdução de novos métodos para calcular e pagar os salários, pela
promoção de rivalidade entre trabalhadores nacionais e
imigrantes, pela invenção de grande número de organismos de
participação e deliberação, pela promulgação de políticas salariais
ou "contratos sociais" etc.) (Mandel, 1982, p.341).

Portanto, essas mudanças que têm ocorrido nos processos de trabalho criam instabilidade e insegurança para uma grande parcela da sociedade decorrentes também das novas formas de contratação, a exemplo dos trabalhadores regidos por contratos temporários, os subcontratados ou terceirizados e que se inserem no mundo do trabalho vivenciando a perda de direitos historicamente conquistados, que por sua vez têm enfraquecido os movimentos de lutas pela garantia e ampliação de direitos dos trabalhadores na medida em que a luta pela sobrevivência acaba se sobrepondo à luta por direitos. Tal tendência, além de gerar um retrocesso dada a diminuição da articulação dos trabalhadores e insegurança destes no que se refere às condições mínimas de sobrevivência, aumenta ainda mais a precarização do trabalho e a exploração do capital em relação à força-de-trabalho humana, tanto em países de capitalismo central quanto em países de economia periférica (Antunes, 1998, p. 235).

Neste sentido é que surgem estratégias para naturalização das relações contraditórias da sociedade capitalista e discursos que enfatizam a ideia de que o indivíduo por suas próprias habilidades pode criar formas de enriquecer e superar os 
entraves sociais. É nesta linha que surge, por exemplo, a retórica do empreendedorismo e da responsabilidade social. Estratégias funcionais ao capital que mistificam a relação contraditória capital/trabalho.

O primeiro parte de uma noção de que todos são iguais em condições de viver e de se desenvolver por suas próprias capacidades, que basta apenas o indivíduo ter "visão de conquista, de avanço" que ele irá conseguir se estruturar em uma sociedade onde todos têm oportunidades, sendo suficiente usar a sua criatividade:

\begin{abstract}
Empreendedorismo é a habilidade de criar e constituir algo a partir de muito ou pouco ou do quase nada. Fundamentalmente, o empreendedor é um ato criativo. É a concentração de energia no iniciar e continuar um empreendimento. É o desenvolver de uma organização em oposição a observá-la, analisá-la ou descrevê-la. Mas é também a sensibilidade individual para perceber uma oportunidade quando outros enxergam caos, contradição e confusão. É o possuir de competências para descobrir e controlar recursos aplicando-os de forma produtiva. (Schlindwein, 2004, p.75)
\end{abstract}

Tal estratégia ganhou mais força no Brasil a partir da década de 1990, momento de profunda reestruturação produtiva e de total abertura brasileira aos ditames internacionais, dos quais a ideologia neoliberal foi uma delas.

Foi neste momento que estratégias de "gestão" da força de trabalho também ganharam mais força como os programas de qualidade total, os sistemas just-in-time e outras formas de estímulo do trabalhador à produtividade a exemplo dos ganhos salariais em torno do cumprimento de metas.

E devido aos altos índices de desemprego em países como o Brasil, o empreendedorismo aparece como uma alternativa a esta dura realidade que na verdade representa muito mais uma forma de sobrevivência.

Aliada a essa ideia de empreendedorismo encontramos disseminado também o discurso da "autonomia" significando na perspectiva dominante que as pessoas podem ser capitalistas, podem enriquecer montando seu "próprio negócio".

Nesses termos, os indivíduos considerados autônomos são na verdade os trabalhadores que se inserem numa relação de compra e venda da sua força de trabalho, mas sem um mínimo de regulação contratual ou proteção trabalhista.

Sob essa ótica, Alves, aponta que 
O indivíduo que se autoemprega, mesmo que sua atividade não seja interior à produção capitalista, não é nem autônomo nem capitalista. Tal qual um assalariado, o produto de seu trabalho será enlaçado pela lógica do capital. O mercado é o ponto para o qual todos convergem e no qual todas as pseudoautonomias se dissolvem. Por mais independente que o indivíduo imagine ser, o produto do seu trabalho terá, em algum momento, de se confrontar com outros, no mercado, onde cada troca imprime a presença da mais-valia, expressando, portanto, a oposição do capital à capacidade viva de trabalho. (Alves, 2006, p. 441)

Ainda sob essa orientação é que o capital promove o que hoje é denominado de terceirização, uma forma legalizada de o capital explorar a força de trabalho com custos significativamente reduzidos. Para a empresa, um ótimo negócio na medida em que não se responsabiliza pelas condições de trabalho em que as atividades são realizadas; para o trabalhador, o lado mais fraco, uma insegurança total (renda, vínculos empregatícios, etc) na medida em que o mesmo é pago por "serviço prestado" ou recebe seu salário por tempo, "forma metamorfoseada do valor ou preço da força de trabalho" (Marx, 1996, p. 139).

Por outro lado, podemos citar ainda como uma forma de "gestão" dos trabalhadores também a chamada "responsabilidade social", outra estratégia funcional ao capital que enfatiza a ideia de que a pobreza e todas as mazelas sociais podem ser superadas a partir da ajuda mútua entre os indivíduos.

Neste âmbito é que entra a filantropia empresarial que estimula principalmente os funcionários a usar o seu "tempo livre" para concretização de "mudanças sociais". Tal estratégia é assim um mecanismo de captura da subjetividade do trabalhador que ilusoriamente se sente como alguém que está colaborando para o bem da sociedade produzindo assim um consentimento do trabalhador aos objetivos empresariais. Como observa Mota,

As estratégias utilizadas pelo grande capital para redefinir socialmente o processo de produção de mercadorias, a rigor, evidenciam as reais necessidades do processo de reestruturação produtiva, a integração passiva dos trabalhadores à nova ordem do capital, isto é, a adesão e o consentimento do trabalhador às exigências da produção capitalista. (Mota, 1996, p.10)

Atrelada a essas estratégias, cito também a noção de empowerment ou empoderamento. Uma ideia difundida principalmente no âmbito empresarial numa aparente lógica de autonomia, poder e participação dos funcionários na administração 
das empresas. Tem como pilares alguns conceitos como autonomia, desenvolvimento profissional, autoconfiança, proatividade e clima organizacional.

Na verdade, a noção de empowerment cria um sentimento de que o funcionário (chamado de "colaborador") é dono também da empresa e participa de todas as decisões e dos lucros, o que é benéfico para o empresário que se sinta dessa forma. Primeiro, porque dentro desta concepção não é necessária a presença ou interferência constante do gestor ou supervisor como na época do fordismo em que era crucial a presença de alguém supervisionando ritmos e tarefas. Segundo, por que acreditando este trabalhador que é autônomo e que tem poder de decisão em torno dos objetivos empresariais, este realiza suas tarefas de uma maneira totalmente comprometida não apenas no aspecto físico, mas também subjetivo.

É assim a constituição de um perfil de trabalhador ideal para o capital. Um trabalhador que se autodisciplina para a realização das tarefas, que toma decisões em favor da empresa, que se adapte aos processos de organização do trabalho e que tenha iniciativa para resolver problemas que dele surgem.

\section{Formas de "gestão" do trabalhador na rede de supermercados Mateus}

O Mateus supermercados é uma empresa com cerca de 51 estabelecimentos nos estados do Maranhão, Pará e Piauí. Considerada a 21 a maior empresa varejista do país, possui cerca de 20.000 (vinte mil) funcionários trabalhando em diversos setores que vão desde a área de vendas até o setor de Responsabilidade Social.

Em entrevista com uma das funcionárias do setor administrativo dos Supermercados Mateus a mesma nos informou sobre alguns aspectos organizacionais da empresa.

O primeiro aspecto que chama atenção é o fato de a empresa ser identificada por todos como "Grupo Mateus" ou "Família Mateus" e que os trabalhadores são chamados de "colaboradores", evidente em todas as falas da entrevistada. 
Neste sentido, em consonância com as atuais configurações do capitalismo, a forma como é denominada a empresa e os trabalhadores deve favorecer a noção de que a relação patrão/empregado não é conflituosa. Também deve favorecer a ideia de que todos fazem parte de uma família com interesses e objetivos comuns.

Um dos pontos também destacados pela entrevistada é que existe uma política interna de cumprimento de metas de dois tipos, uma referente a despesas e outra relacionada a vendas mensais.

A primeira diz respeito, por exemplo, a gastar o mínimo possível com materiais de escritório ou EPI's (Equipamentos de Proteção Individual) por exemplo, além de outros itens. A segunda se refere a atingir metas de vendas por setor, como, por exemplo, o setor de padarias que tem metas de venda de $\mathrm{R} \$ 400.000$ a $\mathrm{R} \$ 500.000$ por loja.

Sobre as metas, a entrevistada informou que existe premiação para o funcionário que atingir a meta mensal. No caso, o valor da premiação é $\mathrm{R} \$ 150$ (cento e cinquenta reais) acrescido ao salário no final do mês. Valor irrisório diante de uma meta alcançada como a apontada anteriormente e diante de um faturamento anual de cerca R\$ 8 bilhões (Jornal Pequeno, 2018).

Neste sentido, podemos perceber que, na empresa referida, uma das estratégias fundamentais para aumento da produtividade do trabalhador é o cumprimento de metas com adicionais no salário do trabalhador, segundo a qual, em última instância, quem lucra é a empresa.

Em relação ao cumprimento de metas, podemos ainda refletir que as mesmas acabam por trazer um sofrimento ao trabalhador que se sente responsável e pressionado a cumpri-las como pode ser observado na fala da entrevistada:

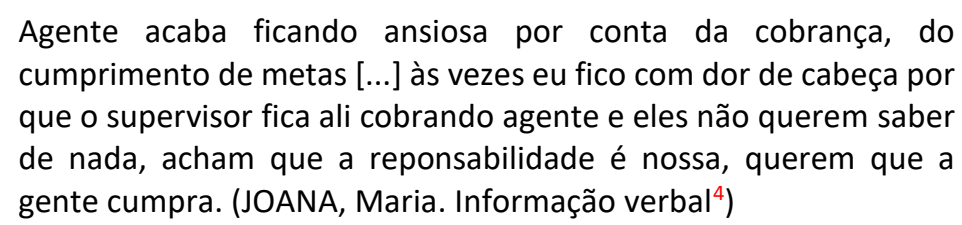

Outro ponto destacado pela entrevistada é o setor de marketing da empresa, tanto externo quanto interno. Em relação ao externo, a funcionária nos afirmou que a

\footnotetext{
${ }^{4}$ Informação concedida em entrevista às autoras.
} 
empresa tem um setor de responsabilidade social que realiza ações em alguns bairros mais carentes ou instituições filantrópicas. A principal atividade deste setor é executar projetos como os denominados "Abraçando Vidas" ou "Natal Social" cujas atividades principais são a doação de alimentos e produtos de higiene pessoal como fraldas, sabonetes, etc.

Destaca-se neste ínterim que os produtos doados são os avariados que não servem mais para ser vendidos. Também, conforme afirmado pela funcionária, os coordenadores dos setores convocam funcionários para trabalhar voluntariamente nos projetos e que inclusive existe um banco de dados em que são cadastrados funcionários que tenham "habilidades para os projetos sociais" como por exemplo aqueles que sabem cantar, dançar, contar histórias, etc.

Em relação ainda ao Marketing, a funcionária destacou que existe também um setor de marketing interno chamado "Endomarketing" responsável dentre outas coisas pelo "bem-estar" do trabalhador. É um setor que realiza atividades de lazer como torneio de futebol ente os funcionários, comemoração de aniversariantes, dia das mães, dos pais, das crianças, etc... Também são realizadas "parcerias" com salões de beleza, lojas de roupas, instituições educacionais para que os funcionários que procurem esses serviços das parcerias recebam desconto. Tal estratégia facilita assim o engajamento do trabalhador que se sente como importante para a empresa e beneficiado por esta.

Também se destaca na fala da entrevistada outro setor responsável pela capacitação e treinamento de funcionários chamado TED (Treinamento e Desenvolvimento). Suas principais funções são realizar palestras e treinamentos para os funcionários. Recentemente, conforme informação dada pela funcionária, a empresa também criou um aplicativo para celular com alguns cursos disponíveis relacionados a "como vender bem", "como atender melhor o cliente", "como falar bem", etc... para que os funcionários de todos os setores estivessem fazendo os cursos nas horas "livres" e que não fosse necessário que os mesmo saíssem do horário de expediente para ouvir palestras. Desse modo, houve logo no início da implantação do aplicativo um estímulo para os funcionários: o setor que fizesse todos os cursos disponíveis no menor tempo possível iria receber uma premiação de $\mathrm{R} \$ 1000$ (mil reais). 
Estas são, portanto algumas das formas de "gestão" utilizadas na empresa Mateus Supermercados, as quais representam estratégias de cooptação do trabalhador para o alcance dos objetivos da empresa, para aumento da produtividade, além de favorecer a falsa ideia de colaboração entre patrão e empregado.

\section{Considerações finais}

A temática trabalho é um dos grandes desafios a ser discutido tendo em vista o contexto em que vivemos de inúmeras contradições.

Os atuais processos em relação ao trabalho apontados neste artigo que vão desde a terceirização até as formas de controle sobre a subjetividade do trabalhador representam assim estratégias do capital para que este continue se expandindo e dominando ao mesmo tempo em que busca enfraquecer a consciência dos trabalhadores sobre o controle que exerce sobre os mesmos.

Desse modo, entendemos que inicialmente a tomada de consciência da classe trabalhadora sobre o controle do capital seria fundamental, além de uma organização política desta classe como forma de resistência a este sistema que tem avançado de tal forma que vem assumindo controle em todas as esferas da vida.

Nestas circunstâncias, devido à insegurança a que está submetida grande parte dos trabalhadores, devido à ausência ou fragilidade de vínculos empregatícios, há um enfraquecimento dos organismos de representação da classe trabalhadora. Portanto, refletir sobre esta realidade é de fundamental importância na defesa e efetivação dos direitos das classes populares.

\section{Referências bibliográficas}

Antunes, Ricardo. 2015. Adeus ao trabalho? Ensaio sobre as metamorfoses e centralidade do mundo do trabalho. São Paulo: Cortez.

Antunes, Ricardo. 1999. Os sentidos do trabalho: ensaio sobre a afirmação e negação do trabalho. São Paulo: Boitempo.

Antunes, Ricardo. 2005. O caracol e sua concha: ensaios sobre a nova morfologia do trabalho. São Paulo: Boitempo. 
Bouillerce, Brigitte. 2004. Saber desenvolver a criatividade na vida e no trabalho. São Paulo: Larousse.

Cungi, Crarly. 2004. Saber administrar o estresse na vida e no trabalho. São Paulo: Larousse.

Dal Rosso, Sadi. 2008. Mais trabalho! A intensificação do labor na sociedade contemporânea. São Paulo: Boitempo.

Dejours, Christophe. 2015. A loucura do trabalho: estudo da psicopatologia do trabalho. São Paulo: Cortez.

Emir, Aquiles. 2017. Ilson Mateus estima faturar em 2017, no mínimo, $R \$ 8$ bilhões. Disponível em: $\quad$ http://maranhaohoje.com/ilson-mateus-estima-fechar-o-ano-de-2017-com-umfaturamento-de-no-minimo-r-8-bilhoes Acesso em 18 de agosto de 2018.

Estadão. Ações trabalhistas caem mais de $50 \%$ após reforma. Disponível em: https: ||veja.abril.com.br|economia|acoes-trabalhistas-caem-mais-de-50-após-reforma Acesso em 20 de fevereiro de 2018.

Gramsci, Antonio. 2001. Americanismo e Fordismo. In Gramsci, Antonio. Cadernos do Cárcere, Vol 4. Rio de Janeiro: Civilização Brasileira.

Gramsci, Antonio. 2000. Cadernos do Cárcere, Vol 3. Rio de Janeiro: Civilização Brasileira.

Harvey, David. 1982. "O Trabalho, o Capital e o Conflito de Classes em torno do Ambiente Construído em Sociedades Capitalistas Avançadas". Revista Espaço \& Debates, n 6, p. 6-35.

Harvey, David. 1992. Condição pós-moderna: uma pesquisa sobre as origens da mudança cultural. São Paulo: Loyola.

Marx, Karl. 1985. O Capital: crítica da economia política, Vol. I, Tomo I. São Paulo: Abril Cultural.

Marx, Karl. 1996. O Capital: crítica da economia política, Livro I, Tomo II. São Paulo: Abril Cultural.

Marx, Karl. 2008. O Capital: crítica da economia política, Livro I, Volume I: O processo de produção capitalista. Rio de Janeiro: Civilização Brasileira.

Mandel, Ernest. 1982. "O Estado na fase do capitalismo tardio". In Mandel, Ernest. O capitalismo tardio. São Paulo: Abril cultural.

Mészàros, István. 2002. "A necessidade e controle social”, In Mészàros, István. Para além do capital. São Paulo: Boitempo.

Minarelli, José Augusto. 1995. Empregabilidade -como ter trabalho e remuneração sempre. São Paulo: Gente.

Mota, Ana Elizabeth. 1996. "Proposta básica para o projeto de formação profissional". Serviço Social e Sociedade, $\mathrm{n}^{\circ} 50$.

Schlindwein, Clainton. 2004. Empreendedores, o desafio do negócio próprio: uma análise da criação de micro e pequenas empresas. Dissertação apresentada à Universidade Federal e Santa Catarina para obtenção do grau de Mestre em Engenharia de Produção. 
Vasapollo, Luciano. 2006. "O trabalho atípico e a precariedade: elemento estratégico determinante do capital no paradigma pós-fordista", In Antunes, Ricardo (Org.) Riqueza e miséria do trabalho no Brasil. São Paulo: Boitempo.

Tramitação do artigo na revista Submetido: $27 / 04 / 2018$

Revisões requeridas: 31/05/2018

Versão revista: 25/06/2018

Aceito: 26/06/2018 